\title{
O MAR, A NAU, A BATALHA: A SOBREVIVÊNCIA DAS FORMAS NA ANTOLOGIA DA MEMÓRIA POÉTICA DA GUERRA COLONIAL
}

\author{
THE SEA, THE SHIP, THE BATLE: \\ SURVIVAL OF FORMS IN \\ ANTOLOGIA DA MEMÓRIA POÉTICA DA \\ GUERRA COLONIAL
}

Lisa Carvalho Vasconcellos ${ }^{1}$

\section{RESUMO}

A Antologia da memória poética da guerra colonial, livro publicado pelos lusitanistas Roberto Vecchi e Margarida Calafate Ribeiro em 2011, é o mais recente esforço no sentido de coletar e dar significado ao enorme corpus poético que foi produzido a partir dos conflitos travados entre Portugal e suas ex-colônias nas décadas de 1960 e 70 . Entre os muitos eixos temáticos e formais que atravessam os poemas e poéticas recolhidos no livro, o resgate e a reproposição da tradição literária portuguesa talvez sejam os principais. Nas mais de seiscentas páginas do volume, as tradições do passado - as Cantigas de Amigo, as crônicas de navegação, a épica camoniana, as figuras históricas e os mitos heroicos - são revistas de modo crítico e inventivo. Mais do que uma releitura paródica do passado, a presença de elementos arcaicos e tradicionais na Antologia denota a sobrevivência de formas e tensões (cf. Aby Warburg) na cultura literária de Portugal, que se renova e reinventa a partir quase sempre das mesmas questões (o mar, a conquista, a saudade e a destruição).

PALAVRAS-CHAVE: poesia; sobrevivência; Guerra Colonial 


\section{ABSTRACT}

The book Antologia da memória poética da guerra colonial was published in 2011 by Roberto Vecchi and Margarida Calafate Ribeiro. As a poetry anthology, its purpose was to collect and give meaning to the poetical material that was created and inspired by the wars that have taken place in 1962-74 between Portugal and it's old colonies. Among the many themes and problems proposed by the poems compiled in the volume, the review and the reclaim of the ancient Portuguese literary tradition is the one that interest us. In Antologia da memória poética da guerra colonial, the old literary forms - the Galician-Portuguese love lyric, the navigation chronicles, The Lusiads', the historical figures and heroic myths - are revisited in a creative and imaginative way. Our hypothesis is that the presence of archaic and traditional elements in the Antologia indicates a form of survival ( $\mathrm{Na}$ chleben) of past forms and tensions (cf. Aby Warburg), they are the traces of a literary tradition that renews itself from the same points (the sea, the conquer, the lost and the destruction).

KEYWORDS: poetry; survival; Portuguese Colonial War

Em 2015, comemoraram-se os quarenta anos da independência de Angola, Moçambique e Guiné-Bissau. Dos muitos eventos que elaboraram e prepararam essa grande efeméride, a publicação da Antologia da memória poética da guerra colonial em 2011 é um que merece destaque. O livro não é o primeiro, mas é, até agora, o maior e mais completo esforço já feito no sentido de inventariar e disponibilizar os incontáveis textos poéticos que foram produzidos a partir do conflito. Seu corpus incluiu não só produções saídas em jornais, revistas, livros ou antologias anteriores, mas também poemas achados em diários, cartas, e nas muitas formas de canções de guerra (hinos, protestos) surgidas na época. Os autores representados nesses materiais, por sua vez, são de todos os tipos e qualidades - na Antologia, textos de escritores consagrados convivem lado a lado com o desabafo das vítimas e familiares, ou com os versos simples e anônimos dos soldados.

Segundo os organizadores, Margarida Calafate Ribeiro e Roberto Vecchi, o levantamento desse "imenso, heterogêneo e poeticamente irregular corpus" foi a maneira encontrada de dar conta de uma realidade igualmente desmesurada - a de um conflito que mobilizou algo em torno de um milhão de homens e atingiu praticamente todas as famílias portuguesas. É a impressão afetiva da violência e das perdas provocadas por um evento dessa magnitude que os organizadores quiseram captar. Por essa razão, não se limitaram a buscar textos que dessem testemunho ou fossem documentos de fatos pretéritos (como uma antologia de poesia de guerra normalmente faria); mas procuraram compor "um modo de conservação e transmissão" da experiência, uma obra que desse "forma - moldura - à 
matéria mnésica, fixando-a e configurando-a" (RIBEIRO; VECCHI, 2011, p. 24). A inclusão da palavra memória já no título do volume procurou dar conta justamente desse aspecto: o que se quis aqui não foi uma antologia de poesia de guerra, mas uma antologia da memória poética da guerra, algo um pouco diferente.

A consequência principal disso é que o livro não se limitou a textos escritos entre os anos de 1961-1974, período em que durou o conflito, entendendo - seguindo Freud ${ }^{2}$ - que a guerra colonial foi um evento cujo teor traumático e avassalador instaurou nos atingidos uma percepção diferente, recorrente e infinita, do tempo do conflito:

\author{
Não sei se alguma vez nós voltaremos \\ da guerra onde deixámos partes d'alma. \\ As minas ainda estão a rebentar \\ trazemo-las por dentro e ninguém pode \\ desarmá-las. \\ A última foi a de Fenando Assis Pacheco \\ não em Zala ou Balacende nem Quilolo \\ mas numa pacata livraria de Lisboa \\ -às onze da manhã \\ Essa hora fatídica da emboscada.
}

Não me venham dizer que foi enfarte Ou acidente cardiovascular. Eu sei Que foi uma mina Armadilhada no coração. (ALEGRE, 2011, p. 381)

O texto do poeta e antigo soldado Manuel Alegre ilustra bem a situação daqueles que foram tocados pela violência desmedida e avassaladora da guerra. O conflito, para ele (e também para o seu colega de armas e letras Fernando Assis Pacheco), não ficou para trás, permanece vivo nas dores do corpo e da alma. As minas, que foram utilizadas aos milhares durante a guerra e que são índice reconhecido de um enfrentamento militar abusivo e injusto, pois que ataca principalmente a população civil deixando mutilações físicas incontornáveis, se tornam então aqui metáfora dos acidentes de um tempo elástico, dentro do qual as explosões seguem despedaçando corações.

É algo próximo dessa concepção de tempo que Ribeiro e Vecchi procuram em seu livro, daí nele serem incluídas produções muito recentes, (a Antologia chega a incluir textos escritos em 2011, data da publicação do livro) e também muito antigas. "O menino de sua mãe", poema de Fernando Pessoa de 1926 é um exemplo do segundo caso. ${ }^{3} \mathrm{Na}$ época da guerra - os editores não especificam a data -, o texto saiu em um álbum musical dedicado a canções sobre o conflito, na interpretação de Dário de Barros. Claramente, a reapropriação para um contexto novo fez com que os versos de Pessoa, que falam sobre um jovem e anônimo soldado morto, se ligas- 
sem também à guerra colonial luso-africana e pudessem então fazer parte do corpus incluído na Antologia.

Dentro desse contexto de tempo infinito, recursivo/recorrente, a reapropriação de formas do passado remoto é uma das estratégias principais e é dela que gostaríamos de falar aqui. Percorrendo as mais de seiscentas páginas da Antologia da memória poética da guerra colonial, chama a atenção o extenso número de produções elaboradas em diálogo com estruturas e conteúdos do cânone tradicional português. Os cantares de amigo, usados como modelo para retratar a dor das mulheres deixadas para trás (RIBEIRO; VECCHI, 2011, p. 53); a épica de Camões, e seu grande manancial de arquétipos coloniais (a África, a viagem, a conquista, o mar) (RIBEIRO; VECCHI, 2011, p. 318); as crônicas de Fernão Lopes e as narrativas das míticas vitórias do passado (RIBEIRO; VECCHI, 2011, p. 320) são só alguns dos cânones recuperados como ponto de interlocução privilegiado pelos mais diferentes autores reunidos na Antologia.

A retomada de formas pretéritas não é feita, porém, sem ambiguidades. Se, por um lado, ela parece assinalar um desejo de continuidade e ligação com o que se foi, por outro, ela também indica rupturas e questionamentos em relação à história oficial do país. Algo parecido já acontecia no romance As naus (1988), de António Lobo Antunes. Nessa narrativa, a chegada dos retornados a Portugal é pontuada pelo reaparecimento de figuras chave, provindas da Era dos Grandes Descobrimentos, como Pedro Álvares Cabral, Vasco da Gama, Manuel de Sousa Sepúlveda e outros. As desventuras desses homens, avesso e paródia dos feitos heroicos do passado, são então desveladas pelo narrador em tom irreverente, que troça do império e seus mitos. Voltando para a Antologia, o que queremos flagrar é como os textos nela recolhidos complexificam essa dinâmica já conhecida, incorporando a tradição não só como referência ou parte de um discurso da memória (por mais ambíguo que esse possa ser), mas também como forma e estrutura poética. A indicação aqui é que o esfacelamento da ordem colonial implica não só o questionamento dos mitos e lendas que estão nas suas origens, mas também a revisão das elaborações linguísticas através das quais esses mesmos mitos se fixaram como modelo para o presente.

A poeta Fiama Hasse Pais Brandão nos dá um bom exemplo de como isso pode acontecer, no poema "Barcas novas", de 1967. Ali, ela toma como epígrafe um poema antigo - mais especificamente uma cantiga de amor de João Zorro - que, citado integralmente, se incorpora ao texto do presente como parte essencial dele.

Barcas novas ${ }^{4}$

Fiama Hasse Pais Brandão

Em Lixboa, sobre o mar

Barcas novas mandei lavrar.

Ai mia senhor velida! 
En Lixboa, sobre lo ler

Barcas novas mandei fazer.

$A i$, mia senhor velida!

Barcas novas mandei lavrar

E no mar as mandei deitar

$A i$, mia senhor velida!

Barcas novas mandei fazer

E no mar as mandei meter.

$A i$, mia senhor velida!

João Zorro

Lisboa tem suas barcas

Agora lavradas de armas

Lisboa tem barcas novas

Agora lavradas de homens

Barcas novas levam guerra

As armas não lavram terra

São de guerra as barcas novas

Ao mar deitadas com homens

Barcas novas são mandadas

Sobre o mar com suas armas

Não lavram terra com elas

Os homens que levam guerra

Nelas mandaram meter

Os homens com sua guerra

Ao mar mandaram as barcas

Novas lavradas de armas

Em Lisboa sobre o mar

Armas novas são mandadas

(BRANDÃO, 2011, p. 37)

Inicialmente, somos levados a ler esse poema a partir dos conceitos de dialogismo e bivocalidade propostos por Bakhtin (2008). Em um movimento paródico, o poema de Fiama toma o texto de João Zorro como ponto de partida, e, usando o mesmo vocabulário e o mesmo estilo da Cantiga de Amor original, cria com ela um diálogo no qual se contrapõem perspectivas passadas e presentes. Na epígrafe, é dado um tema, o do trabalho humano ligado ao mar que se materializa na forma de barcas; no desenvolvimento feito por Fiama, as barcas são qualificadas, não são barcas quaisquer, mas barcas lavradas de armas que partem para destruir. Assim, 
o segundo texto propõe em relação ao primeiro uma mudança significativa: nele o lavrar do poema base - que tem o teor de sacrifício, trabalho e também de oferenda (afinal as barcas parecem estar sendo ofertadas à bela senhora aludida no refrão) - se faz presente, mas ganha por complemento uma série de novos objetos perversos e malignos. Em um movimento de contínuas substituições, que mimetiza em parte a estrutura paralelística da cantiga de Zorro, ${ }^{5}$ a autora termina por fazer com que todos esses termos - a saber, homens, armas, barcas e guerra - se equivalham ao final. O resultado é um suplemento de sentido que subverte a integridade do poema original: o que está aqui em questão não é mais um trabalho que gera valor (barcas), mas um trabalho que produz só perda e morte, uma vez que é um trabalho de guerra.

O contexto português, no qual ambas as produções se inserem, torna essa contraposição particularmente significativa. Lembremos que o trabalho com o mar é uma das tradições mais fortes desse país que é rico em litoral e pobre em terras agricultáveis. Assim, ao se colocarem frente a frente, os dois poemas mostram dois lados (ou ainda, dois momentos) de uma discussão maior que toca questões relativas a história e a identidade nacional portuguesa. No primeiro desses momentos, teríamos representado o mundo da tradição: um mundo no qual os objetos são produzidos a partir de saberes e técnicas aprendidas com os antepassados, carregam uma experiência humana e comunitária, inserindo-se de maneira integrada na vida daqueles que os fabricam e utilizam. Nesse mundo, o poeta, que naturalmente se vincula ao seu meio, aos costumes orais do seu povo e à memória herdada do passado, lembra muito o próprio artesão em seu fazer (BENJAMIN, 1980, p. 63). Em oposição direta e contrária a isso, temos, no segundo momento, o mundo moderno do trabalho reificante e alienado. Aqui, não está em questão a manufatura de um novo objeto que se integra a seu meio (como a barca, que depois de pronta ganha o mar e toca o coração da bela dama do refrão); o lavrar invocado por Fiama não indica um fazer real, mas é metáfora de um antitrabalho (o trabalho de destruição que já mencionamos acima).

O que Fiama Hasse Paes Brandão nos mostra - e a disposição dos dois blocos de texto na página sugere justamente isso - é que os gestos encenados por ela e por Zorro em seus respectivos poemas são equivalentes e complementares. No momento em que o povo português coloca seus barcos no mar, descobre o caminho para as Índias e posteriormente para a América, ele inaugura a empresa colonial. Com ela tem início um grande movimento socioeconômico que culminará não só na subversão de todo um modo de produção tradicional, ${ }^{6}$ mas, em última instância, na própria guerra.

O que temos aqui, ao final das contas, é um modo único de invocar poeticamente uma obra do cânone. Segundo nossa interpretação, o texto de João Zorro não entra aqui como simples ponto de diálogo, ou como referência a ser ratificada ou desconstruída. Ao citar na integralidade a cantiga e dar a ela um espaço na página equivalente a do seu próprio tex- 
to, Fiama a conclama, com toda a sua força, a vir integrar o tempo presente. $O$ resultado é que ela passa a ter, dentro do poema, o mesmo estatuto que os versos da poeta portuguesa, com os quais se conjuga então para formar algo novo. Opostas e espelhadas, a Cantiga de João Zorro e as estrofes de Fiama se unem como as duas metades de um mesmo problema para formar então o texto maior que é "Barcas novas".

Dentro do escopo d'A antologia da memória poética da guerra colonial um outro poema que merece menção é "Explicação de Alcácer Quibir" de Manuel Alegre. No texto, a figura trágica de Dom Sebastião, e a batalha em que ele e grande parte da nobreza portuguesa pereceram, se tornam metáfora não só do fracasso da empresa colonizadora portuguesa, mas de todos os fracassos portugueses através da história. Assim se segue o texto:

Explicação de Alcácer Quibir Manuel Alegre

"A que novos desastres determinas De levar estes reinos e esta gente? Que perigos, que mortes lhe destinas Debaixo dalgum nome preminente?" Camões, Os Lusíadas, canto IV

Quantos desastres dentro de um desastre

Alcácer Quibir foi sempre

o passado por dentro do presente

ó meu país que nunca te encontraste.

Senhor no mar e em terra dependente conquistado de cada vez que conquistaste Alcácer Quibir foi sempre o ires perder-te em cada índia que ganhaste.

Meu cigano do mar. (E o mar foram enganos.)

Alcácer Quibir são as armas vencidas são os ombros vergados e as horas perdidas quinhentos anos dentro destes anos.

Alcácer Quibir é estar aqui a ver morrer o Sol em cada tarde. E este riso que chora. E esta sombra que ri. Este fantasma sobre a nossa idade.

E esta paz como guerra. Este plantar o pão que os outros comem. Este Alentejo desilusão em cada homem.

Estes barcos que partem com homens e armas não já para colher além do mar a terra mas

para levar além do mar a guerra. 
E naufragar de novo. E de novo perder

além do mar o que se deixa em terra (Porque o mais é espuma.)

Alcácer Quibir é ir morrer

além do mar por coisa nenhuma.

Alcácer Quibir és tu - Lisboa ajoelhada

nas armas que em teus barcos vão partir.

Lisboa -Alcácer Quibir

por tuas próprias armas desarmada.

Lisboa ajoelhada nestas armas

que em longes terras vão perder-te. E vão

nos barcos que te levam as naus fantasmas

Com que se foi el-rei Sebastião.

Alcácer Quibir és tu Lisboa.

E há uma rosa de sangue no branco areal.

Há um tempo parado no tempo que voa.

Porque um fantasma é rei de Portugal.

(ALEGRE, 2011, p. 343)

O texto procura unir, em um único movimento, acontecimentos distintos separados por tempo e espaço. Tomando as frases do Velho do Restelo como uma premonição maligna, recolhe sob a rubrica do desastre - um ou vários, tanto faz - as muitas idas e vindas dos barcos e armas, das esperanças e desilusões, das conquistas e derrotas que desembocam sempre em um mesmo resultado, o de uma vitória no além-mar, que é sentida como uma derrota para o povo português que vive no interior. De fato, já foi denunciado - Camões e também Gil Vicente foram dos primeiros a fazerem isso - que as conquistas navais beneficiaram somente uma pequena elite guerreira. Para o resto da população, o saldo foi de recessão econômica (por conta do abandono do campo provocado pela partida dos jovens para o exterior atrás de dinheiro fácil), de perdas e de esquecimento (ARÊAS, 1990, p. 53). A própria epopeia camoniana é, entre outras coisas, um grande lamento aos heróis não reconhecidos da colonização.

Didi-Huberman, em A imagem sobrevivente, explora e desenvolve um dos conceitos mais importantes propostos por Aby Warburg para ler a história da arte ocidental, o de sobrevivência (Nachleben). Analisando arte renascentista, ele se depara com uma quantidade gigantesca de trabalhos que recuperam, lembram, copiam elementos da arte da Roma ou a Grécia antigas. Não entende esse tipo de arte como cópia, influência do passado, para isso seria preciso que o passado estivesse acabado, Warburg, entretanto,

[...] substituiu o modelo natural dos ciclos de "vida e morte", "grandeza e decadência", por um modelo decididamente não natural e simbólico, um modelo cultural da história, no qual os tempos já não eram calcados em estágios biomórficos, 
mas se exprimiam por estratos, blocos híbridos, rizomas, complexidades específicas, retornos frequentemente inesperados e objetivos sempre frustrados. (DIDI-HUBERMAN, 2013, p. 25)

O que Warburg propõe, segundo Didi-Huberman, é que a arte e a cultura não obedeçam a um regime contínuo de temporalidade, mas se pautem pelo tempo do inconsciente. Não é sem razão que a noção de sobrevivência pode ser aproximada ao conceito freudiano de retorno do recalcado. As imagens seguem a lógica dos processos psíquicos complexos, lembram o corpo da histérica que, ao assumir poses diversas - patéticas, teatrais -, se presta como palco de uma encenação na qual é narrada uma história esquecida. Para Didi-Huberman, a imagem sobrevivente é como o sintoma, só se deixa apreender em momentos de crise, quando memórias (que não se equivalem aqui a lembranças) assumem forma plástica e, por meio de "um nó de anacronismos em que se entrelaçam várias temporalidades e vários sistemas de inscrição heterogêneos", deixam surgir o passado.

Parece ser esse o estatuto que a famosa batalha ganha no poema acima; ela ocupa para a história do povo português o mesmo lugar que o trauma teria na narrativa do neurótico: ela é o furo em torno do qual toda a trama se organiza. Tentar tocá-la apreende-la explicá-la - como faz o poeta nos versos que se desdobram sempre com a mesma estrutura "Alcácer Quibir foi"; "Alcácer Quibir são"; "Alcácer Quibir é” - só pode ser feito a partir da recolha de todos os objetos díspares e estranhos que em torno dela gravitam, puxados pela sua força de buraco negro. Assim, o poema amontoa tempos e espaços em uma sucessão em que fracassos económicos, pessoais, identidades geográficas se misturam. Alcácer Quibir é o passado, mas é também a miséria do campo (Alentejo desilusão), é também a melancolia do eu-poeta-soltado que vê o pôr-do-sol com tristeza. É, principalmente, o país a quem o poeta dirige seu lamento, como um novo Velho do Restelo falta é o que nos define.

O resultado é que, por meio da explicação de Manuel Alegre, o evento histórico bem conhecido de todos tem seu sentido deslocado. Ele deixa de ser entendido como um episódio particular - o do conflito que deu fim à vida de muitos, e que lançou o país em um de seus períodos mais terríveis, a União Ibérica -, como querem os manuais de história. No lugar disso, a batalha de Alcácer Quibir se erige aqui como nó que amarra histórias e cronologias diversas, dentro de um campo de amarração no qual tudo parece convergir para ela. Todos os fracassos anteriores vivenciados por Portugal soam, na voz do poeta, como ensaio ou preparação para esse grande fracasso que foi Alcácer Quibir. Por outro lado, todas as derrotas que se seguiram a essa grande derrota modelar parecem copiá-la: "Alcácer Quibir são as armas vencidas/ São os ombros vergados e as horas perdidas/ quinhentos anos dentro desses anos (ALEGRE, 2011, p. 343). O que se tem aqui é uma inversão do vetor do tempo, que parece se voltar sobre si mesmo em um movimento cíclico no qual o fracasso e a negação se dão como eterno retorno. ${ }^{7}$ 
Esses foram dois textos entre os muitos que poderíamos ter estudado aqui. Tentamos mostrar, com suas análises, como, na Antologia da memória poética da guerra colonial. o passado é tomado como arcabouço para pensar e elaborar o presente. Nesse contexto, a revisitação constrói possibilidades de sentidos múltiplas que ligam, em um extremo, a origem perdida do Império e de seu esplendor, recuperável apenas pela imaginação, à outra, na qual se apresenta, de maneira concreta e incrivelmente violenta, o desmantelamento da ordem colonial que perdurou quase até os nossos dias. $\mathrm{O}$ resultado são novas formas de pensar e revisitar o passado, que fogem dos padrões e lugares já conhecidos. As formas da tradição não são aqui somente objeto de um discurso do confronto ou da desconstrução, mas fazem parte de uma concepção de tempo humana e complexa, na qual o passado continua a existir, se não na sua integridade, talvez como resto, caco - estilhaço de mina que depois de implodida habita o corpo do presente.

\section{REFERÊNCIAS BIBLIOGRÁFICA}

ABDALA JR, Benjamin. "Teatro popular e sátira social". In VICENTE, Gil. Auto da Índia; Auto da Barca do Inferno; Farsa de Inês Pereira. São Paulo: SENAC, 1996.

ANTUNES, António Lobo. As naus. 6ª ed. Lisboa: Dom Quixote, 2006.

ARÊAS, Vilma. Iniciação à comédia. Rio de Janeiro: Jorge Zahar Editor, 1990.

BAKHTIN, Mikhail. Problemas da poética de Dostoiévski. Tradução Paulo Bezerra. $2^{\text {a }}$ ed. Rio de Janeiro: Forense Universitária, 1997.

BENJAMIN, Walter. "O narrador. Observações sobre a obra de Nikolai Leskow". In: Textos escolhidos: Walter Benjamin, Max Horkaimer, Theodor Adorno, Jürgen Habermans. Traduções de José Lino Grünnwald [et. al.]. São Paulo: Abril Cultural, 1980, p. 57-74. (Os pensadores).

DIDI-HUBERMAN, Georges. A imagem sobrevivente. História da arte e tempo dos fantasmas segundo Aby Warburg. São Paulo: Contraponto, 2013.

FREUD, Sigmund. O mal-estar na civilização. In: Sigmund Freud. Tradução de Durval Marcondes [at. al.]. São Paulo: Abril Cultural, 1978, p. 129- 194. (Os pensadores).

MOISÉS, Massaud. Dicionário de termos literários. São Paulo: Cultrix, s.d

RIBEIRO, Margarida Calafate; VECCHI, Roberto (Orgs). Antologia da memória poética da Guerra Colonial. Porto: Afrontamento, 2011.

"A memória poética da guerra colonial de Portugal na África: os vestígios como material de uma construção possível” In: Se- 
dlemayer, Sabrina; Ginzburg, Jaime (Org.). Walter Benjamin: rastro, aura, história. Belo Horizonte: UFMG, 2012, p. 87-105.

SIMÕES, João Gaspar. Vida e obra de Fernando Pessoa: história duma geração. Lisboa: Dom Quixote, 1991.

SIMÕES, João Gaspar. Vida e obra de Fernando Pessoa: história de uma geração.

\section{Recebido para publicação em 16/11/2017}

Aprovado em 27/02/2018

\section{NOTAS}

1 Doutora em Teoria Literária e Literatura Comparada pela Universidade de São Paulo. Pesquisadora vinculada ao Grupo de Estudos Comparados de Literaturas de Língua Portuguesa. UFBA/CNPq.

2 Cf. FREUD, Mal-estar na civilização, 1978, p. 136-137

3 O poema original de Fernando Pessoa foi publicado inicialmente na revista Contemporânea em 1926. No texto, o eu-lírico lamenta a sorte de um jovem soldado morto precocemente. Amado e cuidado como filho único que era, ele traz no corpo agora frio as mostras do carinho de sua mãe; esta reza por ele sem se dar conta do seu trágico destino. Sendo um dos principais e mais conhecidos textos de Pessoa, "O menino de sua mãe" foi lido por João Gaspar Simões como um índice dos complexos familiares e carências infantis do próprio autor. Uma aproximação mais contextual do trabalho, entretanto, poderia nos levar a ver nas imagens do jovem corpo loiro e pacífico - que lembra muito a figura descrita no clássico de Arthur Rimbaud, "Dormeur du val" - uma alusão aos soldados alemães massacradas durante a Primeira Guerra Mundial.

4 Tentamos reproduzir a formatação do poema tal qual aparece no livro Antologia da memória poética da guerra colonial.

5 Sem querer entrar na especificidade desse tipo de forma, basta por enquanto dizer que na estrutura paralelística a segunda estrofe de um poema repete quase ao pé da letra a primeira. A variação se concentra em uma única palavra que é normalmente substituída por um sinônimo ou termo de igual categoria. (MOISÉS, s/d). É o que acontece, por exemplo, no poema de João Zorro. Da primeira para a segunda estrofe, vemos que o termo mar é substituído por ler, e lavrar por fazer. Na terceira e quarta estrofes algo semelhante se dá. Esse recurso típico da poesia medieval faz com que o poema seja de fácil memorização e possa ser divulgado sem a necessidade do registro escrito, algo muito importante nas culturas tradicionais que se baseiam na transmissão oral de saberes.

6 Gil Vicente, em sua época, já denunciava as grandes navegações como origem de práticas mercantilistas que pouco beneficiaram Portugal (ABDALA JR, 1996, p. 9). Muito pelo contrário, em busca de lucro fácil, as populações agrárias e urbanas que já rareavam no país abandonaram o campo e as manufaturas. O resultado é um saldo de recessão e descaso, que os lucros das viagens não conseguiram saldar.

7 Uma comparação plausível, mas que infelizmente não poderá ser totalmente desenvolvida aqui, seria entre o estatuto que a batalha de Alcácer Quibir tem no poema de Alegre e a que tem no filme Non ou a vã glória de mandar. No enredo, Manoel de Oliveira, parte 
das conversas entre um grupo de soldados que percorre o interior da África aos finais do conflito colonial para recontar em flashback momentos chave da história portuguesa. $\mathrm{O}$ que une os episódios recuperados do passado, entretanto, não é seu caráter aventuresco ou heroico, mas seu teor de fracasso. A derrota de Viriato, a tentativa falhada de Dom João II de unir Portugal e Castela, se seguem a uma série de eventos falhados que culmina com a própria guerra colonial. No centro dessa terrível cadeia, está a Batalha de Alcácer Quibir. O efeito de espelhamento entre épocas e eventos é acirrado pelo fato de que os atores que atuam como soldados são os mesmos que interpretam as grandes figuras da história portuguesa. O nome do filme Non, um palíndromo inspirado em uma citação de Padre Vieira, é o mote essa história que, como a portuguesa, se volta sobre si mesma em um movimento recursivo de morte e destruição. 